\title{
Clinical profiles and outcome of patients with COVID-19 in a specialized hospital in Japan
}

\author{
Yutaka Oda $^{1}$ (1) $\cdot$ Satoshi Shiraishi ${ }^{2} \cdot$ Motoko Shimada $^{1} \cdot$ Osamu Kurai $^{3}$
}

Received: 27 December 2020 / Accepted: 22 February 2021 / Published online: 4 March 2021

(c) Japanese Society of Anesthesiologists 2021

\begin{abstract}
Purpose To characterize the clinical features and outcome of patients treated at a specialized hospital for coronavirus disease 2019 (COVID-19).

Methods We retrospectively reviewed the symptoms on admission, treatment, and outcome of a total of 300 patients with mild (peripheral oxygen saturation $\left.\left(\mathrm{SpO}_{2}\right) \geq 96 \%\right)$, moderate $\mathrm{I}\left(93 \%<\mathrm{SpO}_{2}<96 \%\right)$, moderate II $\left(\mathrm{SpO}_{2} \leq 93 \%\right)$ and severe (requiring admission to the ICU or mechanical ventilation) COVID-19.

Results Median age was 53 (interquartile range [IQR] 33-72) years and 57\% was male. The number of patients with mild, moderate I, II and severe condition was $85,138,61$ and 16, respectively. Common presenting symptoms were cough $(n=71)$, loss of taste (42), loss of smell (39), fever $\geq 37.5^{\circ} \mathrm{C}$ (36). Dyspnea was observed only 21 cases; 57 reported no symptoms on admission. Favipiravir, ciclesonide, dexamethasone, and heparin were administered in 106, 168, 65, and 38 patients, respectively, but not remdesivir. The median duration of hospitalization was $10(7-15)$ days. All patients with mild and moderate I severity were discharged. Among the 77 patients classified as moderate II or severe, 3 were transferred to tertiary hospitals for further treatment on the day of admission. The respiratory condition worsened in 21 patients; 18 required transfer to tertiary hospitals 3 (median) days after admission and 3 died.

Conclusion Respiratory condition recovered in $92 \%$; whereas it worsened in $7 \%$ and the mortality rate was $1 \%$. The ratios of male patients, of patients with diabetes mellitus in those with the decreased respiratory condition, were significantly higher than recovered.
\end{abstract}

Keywords COVID-19 $\cdot$ Pandemic $\cdot$ Specialized hospital

This study was carried out at the Department of Anesthesiology, Respiratory Medicine, Gastroenterology and Hepatology, Osaka City Juso Hospital

Yutaka Oda

yutakaodayutaka@gmail.com

Satoshi Shiraishi

s-shiraishi@med.osakacity-hp.or.jp

Motoko Shimada

m0m017@hotmail.com

Osamu Kurai

kuraion2@gmail.com

1 Department of Anesthesiology, Osaka City Juso Hospital, 2-12-27 Nonaka-kita, Yodogawa-ku, Osaka 532-0034, Japan

2 Department of Respiratory Medicine, Osaka City Juso Hospital, Osaka, Japan

3 Department of Gastroenterology and Hepatology, Osaka City Juso Hospital, Osaka, Japan
Coronavirus disease 2019 (COVID-19) is a global pandemic and nearly 73 million cases and 1.5 million deaths have been reported worldwide until November $2020 .^{1}$ The clinical spectrum of COVID-19 appears to be wide, encompassing asymptomatic infection, mild upper respiratory tract illness, and severe viral pneumonia with respiratory failure and even death [1]. A high proportion of patients (10-32\%) requires admission to high dependency or intensive care units [1-3], and the clinical course of those patients, prognostic factors have been repeatedly reported $[2,4,5]$. On the other hand, despite an increasing importance of neighboring hospitals for initial treatment with an outbreak of COVID-19, profiles and clinical course of patients in those hospitals with a wide range of severity are less reported [6,7]. We aimed to explore the clinical, laboratory characteristics and outcome of patients at the first Japanese hospital designated to treat COVID-19 patients.

\footnotetext{
${ }^{1}$ https://coronavirus.jhu.edu/map.html, accessed Dec. 16, 2020.
} 


\section{Methods}

This is a retrospective, observational study at Osaka City Joso Hospital, a public hospital located in the north of Osaka prefecture with a population of 8.8 million. Ours was the first hospital in Japan dedicated to COVID-19 patients when the system was started. It was initially scheduled to admit a maximum of 20 patients, which was expanded to 70 later. After obtaining approval from the institutional ethics committee (No. 2-5, September 28, 2020), all consecutive patients who were admitted to our hospital during the period from March 25 to September 14, phase 2 of COVID-19 pandemic, were included in the study. Written informed consent from each patient was waived by opting out.

\section{Profiles of patients}

People with suspected COVID-19 infection underwent reverse transcription-polymerase chain reaction (RT-PCR) test of a nasopharyngeal sample for SARS-CoV-2 at hospitals, clinics and drive-through testing stations. Information of all infected patients is collected at the Osaka Prefectural Follow-up Center via the local public health centers in each city, and triage doctors order them to stay home, in the hotels, to be admitted to hospitals providing regular medical care or tertiary hospitals, according to the severity classification made by the Ministry of Health, Labour and Welfare, ${ }^{2}$ where mild, peripheral oxygen saturation $\left(\mathrm{SpO}_{2}\right) \geq 96 \%$, with no respiratory symptoms or coughing only, no shortness of breath; moderate I (patient does not suffer respiratory failure), $93 \%<\mathrm{SpO}_{2}<96 \%$, with shortness of breath and pneumonia findings; moderate II (patient suffers respiratory failure), $\mathrm{SpO}_{2} \leq 93 \%$ and oxygen administration is required; severe, requiring admission to the ICU or mechanical ventilation. Our hospital, as one of the neighboring hospitals, mainly received patients with COVID-19 of mild, moderate I or II severity, and those with severe COVID-19 requiring no life-prolonging treatment.

\section{Treatment}

Blood test, chest X-ray, and if required, CT scan were performed on admission. Symptoms and complaints on admission were recorded by the attending nurses. Supplemental oxygen was administered in order to maintain $\mathrm{SpO}_{2} \geq 93 \%$. Patients received medications for COVID-19 pneumonia according to the methods suggested by the Ministry of Health, Labour and Welfare (see Footnote 2). Oral favipiravir, an RNA polymerase inhibitor, and inhalational

\footnotetext{
2 https://www.mhlw.go.jp/content/000646531.pdf, accessed Dec. 23, 2020 .
}

ciclesonide, corticosteroid for bronchial asthma, were administered in the form of a clinical trial after obtaining approval from the ethics committee of our institute (No. 1-10 and 1-11, respectively, March 30, 2020) as well as from each patient, based on the decision by the individual physicians. Intravenous dexamethasone $6.6 \mathrm{mg} /$ day was administered for 10 days in case $\mathrm{SpO}_{2}$ decreased below $93 \%$ with inhalational oxygen. Subcutaneous heparin 10,000 units/day was added to dexamethasone in patients with abnormal increase of plasma fibrinogen. Remdesivir was not used because its use has been limited to those with severe cases requiring the introduction of extracorporeal membrane oxygenation or mechanical ventilation. In case a decrease of $\mathrm{SpO}_{2}$ below $93 \%$ with inhalational oxygen at $5 \mathrm{~L} / \mathrm{min}$ lasted for $>12 \mathrm{~h}$, patients were transferred to tertiary hospitals for intensive care unless they required no life-prolonging treatment. Discharge criteria were (1) 10 days after the date of onset and $72 \mathrm{~h}$ after the resolution of symptoms, or (2) $24 \mathrm{~h}$ after the resolution of symptoms if the patient has tested negative for the PCR test twice with at least $24 \mathrm{~h}$ between tests (see Footnote 2). The last follow-up date was October 2020, when all the subjects were discharged or died.

\section{Data collection and statistical analysis}

We collected data from the electronic medical records (MegaOak, NEC Corporation, Tokyo). Information of past histories was obtained from the patients, their families, and previous institutes where they stayed. We did not calculate the Sequential Organ Failure Assessment Score or APACHE II score because consciousness disturbance or hypotension was observed in no patients on admission, and arterial blood gas was not measured in most of them. No statistical sample size calculation was performed a priori owing to the nature of the study. We defined recovery as an improvement of the grade of severity from moderate I or II on admission to mild. Patients' condition was also construed as being recovered if they satisfy the aforementioned criteria for discharge. We defined worsening as $\mathrm{SpO}_{2}$ decreasing to $<93 \%$ with inhalational oxygen at $5 \mathrm{~L} / \mathrm{min}$ for $>12 \mathrm{~h}$.

Statistical analyses were performed by SigmaPlot 12 (Systat Software Inc., San Jose, California, USA). Continuous variables are presented as median (range), if not specified. Categorical variables are presented as frequency (percentage). Categorical data of the severity and outcome among the three age groups were analyzed by chi-square test or Fisher's exact test. For univariate comparisons between patients with recovered and worsened respiratory condition Mann-Whitney's $U$-test was used. Duration of hospitalization among the three age groups was analyzed by Kruskal-Wallis test, followed by Dunn's multiple comparisons. $P<0.05$ was regarded as statistically significant. 
Table 1 Severity on admission, duration of hospitalization, and outcome of the three age groups

\begin{tabular}{|c|c|c|c|c|c|c|c|c|c|c|}
\hline \multirow[t]{2}{*}{ Age } & \multicolumn{5}{|c|}{ Severity on admission } & \multirow{2}{*}{$\begin{array}{l}\text { Duration of hospi- } \\
\text { talization (days) }\end{array}$} & \multicolumn{4}{|l|}{ Outcome } \\
\hline & $\begin{array}{l}\text { Mild } \\
\text { [Mild } \\
\text { I] }\end{array}$ & $\begin{array}{r}\text { M I } \\
+\mathrm{M}\end{array}$ & $\begin{array}{l}\text { M II } \\
{[\mathrm{M} \mathrm{II+}}\end{array}$ & $\begin{array}{l}\text { Severe } \\
\text { severe] }\end{array}$ & Total $(\%)$ & & Improve & Unchange & $\begin{array}{l}\text { Worsen } \\
\text { [worsen }\end{array}$ & $\begin{array}{l}\text { Died } \\
+ \text { died] }\end{array}$ \\
\hline$<40$ & $\begin{array}{l}52 \\
{[88]}\end{array}$ & 36 & $\begin{array}{l}6 \\
{[7]}\end{array}$ & 1 & $95(32 \%)$ & $9([7-12], 1-39)$ & 93 & 1 & $\begin{array}{l}1 \\
{[1]}\end{array}$ & 0 \\
\hline $40-69$ & $\begin{array}{l}19 \\
{[79]}\end{array}$ & 60 & $\begin{array}{l}31 \\
{[38]^{* *}}\end{array}$ & 7 & $117(39 \%)$ & $10([7-18], 1-52)$ & 103 & 1 & $\begin{array}{l}13 \\
{[13]}\end{array}$ & 0 \\
\hline$\leq 70$ & $\begin{array}{l}14 \\
{[56]}\end{array}$ & 42 & $\begin{array}{l}24 \\
{[32]^{* *}}\end{array}$ & 8 & $88(29 \%)$ & $14([9-22], 1-85)^{\ddagger}$ & 80 & 1 & $\begin{array}{l}4 \\
{[7]^{\mathbb{I I}}}\end{array}$ & 3 \\
\hline Total & $\begin{array}{l}85 \\
{[223]}\end{array}$ & 138 & $\begin{array}{l}61 \\
{[77]}\end{array}$ & 16 & 300 & $10([7-15], 1-85)$ & 276 & 3 & 18 & 3 \\
\hline
\end{tabular}

The number of patients is expressed as the absolute value (percentage), [sum of the two severity groups] or [sum of the worsen and died]. The duration of hospitalization is expressed as median days ([25-75\% interquartile range], range)

$M I$ moderate I, $M$ II moderate II

** $P<0.001$ compared with the ratio of patients to the total number in the age group $<40$ years

${ }^{\ddagger} P<0.001$ compared with the duration of hospitalization of patients $<40$ years and $40-69$ years

${ }^{\mathbb{I}} P=0.03$ compared with the ratio of patients in the age group $<40$ years

\section{Results}

\section{Profiles}

A total of 300 patients, including one who was readmitted and calculated as two individuals, were included (median age, 53 years [interquartile range $\{\mathrm{IQR}\}, 33-72$; range 15-100 years]; $57 \%$ male). The median time from illness onset to admission was 7 (IQR, 4-9; range, 1-44) days, including a young female in whom results of the retest for SARS-CoV-2 RNA was positive and was admitted to our hospital 44 days after initial onset. Among the 300 patients, 223 (74\%) including 10 pregnant women were classified as mild or moderate I severity ( $n=85$ and 138, respectively) requiring no supplemental oxygen, and the remaining 77 patients were accompanied with moderate II or severe respiratory condition ( $n=61$ and 16, respectively, Table 1$)$. Of the 16 patients with a severe condition on admission, 13 $(81 \%)$ were transferred from tertiary hospitals, of whom 10 patients had undergone mechanical ventilation under tracheal intubation in those hospitals. They were still requiring supplemental oxygen $\geq 5 \mathrm{~L} / \mathrm{min}$ for maintaining $\mathrm{SpO}_{2} \geq 93 \%$ after extubation.

The ratio of patients classified as moderate II or severe condition to the total number of patients between 40 and 69 years (38/117) and $\geq 70$ years (32/88) was significantly higher than those $<40$ years $(7 / 95)(P<0.001$ for both, Table 1). Patients had been staying in their homes (206 [69\%]), hospitals (62 [21\%]), hotels (16 [5\%]) or care homes (16 [5\%]) before admission to our hospital. A cluster of
COVID-19 cases occurred in hospitals and care homes, from where 31 patients were transferred to our hospital. Among the 62 patients who had been staying in other hospitals, 34 were transferred for treatment of COVID-19 based on the positive results of RT-PCR; the remaining 28 were for follow-up treatment of COVID-19 after recovering from severe stage in the tertiary hospitals in Osaka.

\section{Symptoms and laboratory data}

Common presenting symptoms on admission were cough, loss of taste, loss of smell, fever $\geq 37.5^{\circ} \mathrm{C}$, and general fatigue. Only 21 (7\%), much fewer than 77 cases with moderate II or severe condition, complained of dyspnea (Table 2). Notably, 57 (19\%) cases reported no symptoms on admission. The most common comorbidities were hypertension, followed by diabetes mellitus, cerebral vascular disease and dementia. Chest XP demonstrated abnormal shadows indicative of pneumonia in 186 (62\%) patients. Ground-glass opacity and consolidation typical for COVID-19 pneumonia were detected in $177(83 \%)$ of a total of 214 patients underwent chest CT scan. More than $50 \%$ of the patients presented with abnormally increased levels of C-reactive protein (CRP), ferritin, and fibrinogen within $4 \mathrm{~h}$ after admission (Table 3). Lymphocytopenia $\left(<1.1 \times 10^{9} / \mathrm{L}\right)$ was detected in $44 \%$.

\section{Treatment and outcome}

The median duration of hospitalization of all patients was 10 (IQR, 7-15; range, 1-85) days (Table 1). It was significantly 
Table 2 Symptoms on admission and comorbidities

\begin{tabular}{lc}
\hline Symptoms & \\
Cough & $71(24)$ \\
Loss of taste & $42(14)$ \\
Loss of smell & $39(13)$ \\
Fever $\geq 37.5^{\circ} \mathrm{C}$ & $36(12)$ \\
General fatigue & $36(12)$ \\
Dyspnea & $21(7)$ \\
Comorbidities & \\
Hypertension & $68(23)$ \\
Diabetes mellitus & $60(20)$ \\
Cerebral vascular disease without dementia & $13(4)$ \\
Dementia & $12(4)$ \\
Psychiatric disease & $9(3)$ \\
Chronic obstructive lung disease & $8(3)$ \\
Ischemic heart disease & $7(2)$ \\
Chronic heart failure & $7(2)$ \\
Obstructive sleep apnea & $6(2)$ \\
\hline
\end{tabular}

Data are expressed as the number of patients (percentage)

longer in patients $\geq 70$ years than in those $<40$ years and 40-69 years (14 vs. 9 and 14 vs. 10 days, $P<0.001$ for both). Favipiravir, ciclesonide, dexamethasone and heparin were administered in 106 (35\%), 168 (56\%), 65 (22\%), and 38 (13\%) patients, respectively.

Respiratory condition recovered in 276 (92\%) patients including all cases with mild and moderate I severity on admission $(n=223)$. Of those 276 patients, 229 were discharged home; 33 and 14 were discharged to outside hospitals and nursing facilities, respectively, because of difficulties in daily life after discharge. Most of them stayed in hospitals and nursing homes before transferring to our hospital. In two males initially classified as moderate II and severe, the respiratory condition was poorer than the prehospital information reported by the triage doctor and both of them apparently required tracheal intubation soon after arrival at our hospital. A 30-year-old pregnant woman (36 weeks and 1 day) was transferred from a university hospital. Although the initial classification of severity was moderate II, she developed remarkable tachypnea with $\mathrm{SpO}_{2}<93 \%$ with supplemental oxygen $1 \mathrm{~h}$ after arrival at our hospital, suggesting that her condition was severe. These three patients were transferred to tertiary hospitals with unchanged conditions on the day of admission to our hospital and were excluded from the outcome evaluation.

Among the 74 patients classified as moderate II and severe COVID-19 ( $n=59$ and 15 , respectively), the respiratory condition worsened in 21 patients (initial classification: mild II, 16 and severe, 5) during hospitalization (Table 1); 18 of them were urgently transferred to tertiary hospitals after staying $3(1-7)$ days, and 3 (85, 85 and
Table 3 Laboratory data on admission

\begin{tabular}{lc}
\hline White blood cell count, $\times 10^{9} / \mathrm{L}$ & $5.2(4.0-7.0)$ \\
$<3.6^{*}$ & $45(15 \%)^{*}$ \\
$3.6-8.2$ & $218(73 \%)$ \\
$>8.2^{*}$ & $36(12 \%)^{*}$ \\
Lymphocyte count, $\times 10^{9} / \mathrm{L}$ & $1.2(0.8-1.6)$ \\
$<1.1^{*}$ & $132(44 \%)^{*}$ \\
$\geq 1.1$ & $167(56 \%)$ \\
Aspartate aminotransferase, $\mathrm{U} / \mathrm{L}$ & $27(20-39)$ \\
$\leq 38$ & $224(75 \%)$ \\
$>38^{*}$ & $75(25 \%)^{*}$ \\
Alanine aminotransferase, $\mathrm{U} / \mathrm{L}$ & $24(14-41)$ \\
$\leq 43$ & $231(77 \%)$ \\
$>43^{*}$ & $68(23 \%)^{*}$ \\
Lactate dehydrogenase, $\mathrm{U} / \mathrm{L}$ & $212(173-272)$ \\
$\leq 211$ & $150(50 \%)$ \\
$>211^{*}$ & $149(50 \%)^{*}$ \\
Creatinine, mg/dL & $0.76(0.61-1.0)$ \\
$\leq 0.80$ & $169(57 \%)$ \\
$>0.80^{*}$ & $130(43 \%)^{*}$ \\
C-reactive protein, mg/L & $1.8(0.4-4.0)$ \\
$\leq 0.3$ & $69(23 \%)$ \\
$>0.3^{*}$ & $230(77 \%)^{*}$ \\
Fibrinogen, mg/dL & $420(327-548)$ \\
$\leq 400$ & $132(44 \%)$ \\
$>400^{*}$ & $167(56 \%)^{*}$ \\
D-dimer, $\mu \mathrm{g} / \mathrm{mL}$ & $0.9(0.7-1.0)$ \\
$\leq 1.0$ & $181(61 \%)$ \\
$>1.0^{*}$ & $118(39 \%)^{*}$ \\
Ferritin, ng/mL & $179(40 \%)$ \\
Male & \\
Female & $586.5(354.5-990.3)$ \\
Within normal range & \\
Out of normal range & \\
& \\
&
\end{tabular}

Data are median (interquartile range) or number of patients (\% of those with available data)

*Out of normal range

77 years, all males) who required no life-prolonging treatment died 14-15 days after transferal from other hospitals or from a care home to our hospital. No patients required emergency tracheal intubation, circulatory support or kidney replacement therapy.

Compared with patients who recovered, those with the decreased respiratory condition were significantly older, predominantly male sex, with larger body mass index, and had a higher proportion with diabetes mellitus (Table 4). Compared with patients with recovered respiratory condition, for patients with decreased respiratory condition, aspartate aminotransferase (AST), alanine aminotransferase (ALT), lactate dehydrogenase (LDH), creatinine and inflammation-related indices (CRP, fibrinogen and ferritin), but 
Table 4 Univariate analysis of characteristics, comorbidities, and laboratory data between patients with recovered and worsened respiratory condition

\begin{tabular}{lcccc}
\hline & All $(n=300)$ & Recovered $(n=276)$ & Worsened $(n=21)$ & $P$ value \\
\hline Age (year) & $53(33-72)$ & $52(32-72)$ & $63(48-73)$ & 0.03 \\
Sex (male) & $171(57 \%)$ & $150(54 \%)$ & $20(95 \%)$ & $<0.001$ \\
Body mass index $\left(\mathrm{kg} / \mathrm{m}^{2}\right)$ & $23(21-26)$ & $23(21-26)$ & $25(24-26)$ & 0.04 \\
Comorbidities & & & \\
Hypertension & $68(23 \%)$ & $62(21 \%)$ & $6(29 \%)$ & 0.3 \\
Diabetes mellitus & $60(20 \%)$ & $50(18 \%)$ & $10(48 \%)$ & 0.003 \\
Laboratory data & & & \\
White blood cell count $\left(\times 10^{9} / \mathrm{L}\right)$ & $5.2(4.0-7.0)$ & $5.2(4.0-6.9)$ & $5.4(5.0-6.7)$ & 0.5 \\
Lymphocyte $\left(\times 10^{9} / \mathrm{L}\right)$ & $1.2(0.9-1.6)$ & $1.2(0.9-1.6)$ & $1.0(0.7-1.4)$ & 0.04 \\
Aspartate aminotransferase $(\mathrm{U} / \mathrm{L})$ & $27(20-39)$ & $27(20-37)$ & $36(31-54)$ & $<0.001$ \\
Alanine aminotransferase $(\mathrm{U} / \mathrm{L})$ & $24(14-41)$ & $22(13-40)$ & $34(27-57)$ & 0.003 \\
Lactate dehydrogenase $(\mathrm{U} / \mathrm{L})$ & $212(173-272)$ & $209(168-265)$ & $267(221-348)$ & $<0.001$ \\
Creatinine $(\mathrm{mg} / \mathrm{dL})$ & $0.76(0.61-1.00)$ & $0.76(0.61-0.91)$ & $0.83(0.75-0.95)$ & 0.03 \\
C-reactive protein $(\mathrm{mg} / \mathrm{dL})$ & $1.8(0.4-4.5)$ & $1.5(0.3-4.0)$ & $5.2(3.5-9.2)$ & $<0.001$ \\
Fibrinogen $(\mathrm{mg} / \mathrm{dL})$ & $420(327-548)$ & $411(322-531)$ & $548(470-635)$ & $<0.001$ \\
D-dimer $(\mu \mathrm{g} / \mathrm{dL})$ & $0.9(0.7-1.4)$ & $0.9(0.7-1.4)$ & $1.0(0.9-1.6)$ & 0.16 \\
Ferritin $(\mathrm{ng} / \mathrm{mL})$ & $397(189-800)$ & $362(166-733)$ & $1006(530-1409)$ & $<0.001$ \\
\hline
\end{tabular}

Data are expressed as the absolute value (percentage) or median (25-75\% interquartile range) not D-dimer were significantly elevated, lymphocyte counts were significantly decreased.

\section{Discussion}

Our hospital started receiving patients with COVID-19 on March 25, and was transformed into one specialized for COVID-19 since May 1, 2020 with great efforts of all the medical staff. Similar hospitals are also reported in the US and in Italy [6, 7]. Because the cumulative number of patients of COVID-19 was approximately 9600 until September 14 in the Osaka prefecture, ${ }^{3}$ we provided medical care for almost $3 \%$ of the total number of patients in this area.

The mortality rate was only $1 \%$ (3/300), much lower than early reports from China (28\%, from December, 2019 to January, 2020) and from the US (21\%, from March to April, 2020) [8-10], although the distribution of age, the ratio of male sex and comorbidities were similar to those reports. This might result from the small number of patients with severe respiratory dysfunction admitted to our hospital, as supported by the similarly low mortality rate $(1.1 \%)$ in nonsevere cases in China [5]. The global mortality rate in Japan is approximately $1.5 \%$, still lower than other countries (see Footnote 1). This might result from the reduced susceptibility to COVID-19 due to angiotensin-converting enzyme 2 receptor expression and/or different human leukocyte

\footnotetext{
${ }^{3}$ https://www3.nhk.or.jp/news/special/coronavirus/data/.
}

antigen (HLA) that confers immune resistance to coronavirus specific for Japanese [11], although the precise reason remains unclear.

All the patients initially classified as mild or moderate I severity ( $n=223$ ) were discharged without requiring invasive respiratory treatment. On the other hand, respiratory condition further deteriorated in 21 out of 74 patients $(28 \%)$ with moderate II or severe respiratory conditions on admission, most of whom required transferal to tertiary hospitals for intensive therapy. This is comparable with the proportion of patients requiring invasive care units among those with a severe condition in the US [2] and in China [5] (17\% for both), suggesting that the low mortality rate in Japan would result from the decreased proportion of patients with the severe respiratory condition compared with other countries. Although the severity classification defined by the Ministry of Health, Labour and Welfare, Japan (see Footnote 2) is different from those used in other studies [12], it would be practical and useful for prompt evaluation and prediction of the prognosis based on this study.

A rapid transferal system to tertiary hospitals would be an urgent issue because most of the surrounding hospitals, including ours, do not have enough capacity including equipment or medical staffs for managing severe cases requiring tracheal intubation, mechanical ventilation, and extracorporeal membrane oxygenation. There were 28 patients who were transferred from the tertiary hospitals after recovery from the severe state. Besides receiving patients with newonset of COVID-19, it is also an important role of our hospital to receive these patients to facilitate the transferal of 
severe patients to tertiary hospitals because of the full capacity of the ICU.

Regarding laboratory data, abnormalities in CRP, LDH, fibrinogen and ferritin were consistent with previous studies $[9,13]$. D-dimer exceeded the normal range $(1.0 \mu \mathrm{g} / \mathrm{dL})$ in $39 \%$ cases in our study, similar to the value reported previously [8]; however, it was not higher in patients whose respiratory condition worsened compared with those recovered in the present study. Possible reasons for this would be that the number of elderly patients $\geq 70$ years was small (29\%) and the outcome was generally favorable. Although few reports evaluate CRP and refer to it in patients with poor prognosis $[13,14]$, it is regulated by inflammatory cytokines such as interleukin- 1 and 6 , and systemic inflammation would significantly contribute to the outcome. Longer elapsed time from the onset of COVID19 to admission (median, 7 days) compared with other reports [2] may be one of the reasons for remarkably elevated CRP.

There are several limitations in this study. This is a retrospective data collection from a small number of patients in a single institute. Most of the patients were classified as mild or moderate severity, and the number of patients with the deteriorated condition or died was too small to elucidate more factors for worsening of the respiratory condition, according to a previous study for statistical analysis [15]. Moreover, the outcome of patients with severe conditions is not known because they were transferred to tertiary care hospitals. The admission policy of patients with COVID19 to our hospital has changed after the completion of this study, to admit patients with moderate severity or those aged $\geq 65$ years on a priority basis because of an increase of affected patients. Patients' profiles and outcomes in our institute remarkably changed after 2020 October.

In conclusion, we received 300 COVID-19 patients with predominantly mild and moderate severity as a specialized hospital. Respiratory conditions worsened in $7 \%$ and in-hospital mortality rate was as low as $1 \%$, probably because of relatively young age. The ratios of male patients, of patients with diabetes mellitus in those with decreased respiratory condition were significantly higher than recovered.

Author contributions YO conceptualized the study. YO, SS, and MS collected data. YO drafted the manuscript and OK provided critical comments.

Data availability The datasets used and/o analyzed during the current study are available from the corresponding author on reasonable request.

\section{Declarations}

Conflict of interests The authors declare that they have no conflict of interests.

\section{References}

1. Huang C, Wang Y, Li X, Ren L, Zhao J, Hu Y, Zhang L, Fan G, Xu J, Gu X, Cheng Z, Yu T, Xia J, Wei Y, Wu W, Xie X, Yin W, Li H, Liu M, Xiao Y, Gao H, Guo L, Xie J, Wang G, Jiang R, Gao Z, Jin Q, Wang J, Cao B. Clinical features of patients infected with 2019 novel coronavirus in Wuhan, China. Lancet. 2020;395:497-506.

2. Docherty AB, Harrison EM, Green CA, Hardwick HE, Pius R, Norman L, Holden KA, Read JM, Dondelinger F, Carson G, Merson L, Lee J, Plotkin D, Sigfrid L, Halpin S, Jackson C, Gamble C, Horby PW, Nguyen-Van-Tam JS, Ho A, Russell CD, Dunning J, Openshaw PJ, Baillie JK, Semple MG, Investigators IC. Features of 20133 UK patients in hospital with covid-19 using the ISARIC WHO clinical characterisation protocol: prospective observational cohort study. BMJ. 2020;369:m1985.

3. Remuzzi A, Remuzzi G. Covid-19 and Italy: what next? Lancet. 2020;395:1225-8.

4. Petrilli CM, Jones SA, Yang J, Rajagopalan H, O'Donnell L, Chernyak Y, Tobin KA, Cerfolio RJ, Francois F, Horwitz LI. Factors associated with hospital admission and critical illness among 5279 people with coronavirus disease 2019 in New York city: prospective cohort study. BMJ. 2020;369:m1966.

5. Li X, Xu S, Yu M, Wang K, Tao Y, Zhou Y, Shi J, Zhou M, Wu B, Yang Z, Zhang C, Yue J, Zhang Z, Renz H, Liu X, Xie J, Xie M, Zhao J. Risk factors for severity and mortality in adult covid-19 inpatients in Wuhan. J Allergy Clin Immunol. 2020;146:110-8.

6. Maniscalco P, Poggiali E, Quattrini F, Ciatti C, Magnacavallo A, Caprioli S, Vadacca G, Michieletti E, Cavanna L, Capelli P. The deep impact of novel covid-19 infection in an orthopedics and traumatology department: the experience of the Piacenza hospital. Acta Biomed. 2020;91:97-105.

7. Miller AO, Kapadia M, Kirksey MA, Sandhu M, Jannat-Khah D, Bui T, Boyle KK, Krez A, Russell L, O’Neill J, Stein EM, Henry MW, Antao VC, Padgett DE. Clinical experience with covid-19 at a specialty orthopedic hospital converted to a pandemic overflow field hospital. HSS J. 2020;16(1):1-7.

8. Zhou F, Yu T, Du R, Fan G, Liu Y, Liu Z, Xiang J, Wang Y, Song B, Gu X, Guan L, Wei Y, Li H, Wu X, Xu J, Tu S, Zhang Y, Chen $\mathrm{H}, \mathrm{Cao}$ B. Clinical course and risk factors for mortality of adult inpatients with covid-19 in Wuhan, China: a retrospective cohort study. Lancet. 2020;395:1054-62.

9. Richardson S, Hirsch JS, Narasimhan M, Crawford JM, McGinn T, Davidson KW, the Northwell C-RC, Barnaby DP, Becker LB, Chelico JD, Cohen SL, Cookingham J, Coppa K, Diefenbach MA, Dominello AJ, Duer-Hefele J, Falzon L, Gitlin J, Hajizadeh N, Harvin TG, Hirschwerk DA, Kim EJ, Kozel ZM, Marrast LM, Mogavero JN, Osorio GA, Qiu M, Zanos TP. Presenting characteristics, comorbidities, and outcomes among 5700 patients hospitalized with covid-19 in the New York City area. JAMA. 2020;323:2052-9.

10. Argenziano MG, Bruce SL, Slater CL, Tiao JR, Baldwin MR, Barr RG, Chang BP, Chau KH, Choi JJ, Gavin N, Goyal P, Mills AM, Patel AA, Romney MS, Safford MM, Schluger NW, Sengupta S, Sobieszczyk ME, Zucker JE, Asadourian PA, Bell FM, Boyd R, Cohen MF, Colquhoun MI, Colville LA, de Jonge JH, Dershowitz LB, Dey SA, Eiseman KA, Girvin ZP, Goni DT, Harb AA, Herzik N, Householder S, Karaaslan LE, Lee H, Lieberman E, Ling A, Lu R, Shou AY, Sisti AC, Snow ZE, Sperring CP, Xiong Y, Zhou HW, Natarajan K, Hripcsak G, Chen R. Characterization and clinical course of 1000 patients with coronavirus disease 2019 in New York: retrospective case series. BMJ. 2020;369:m1996.

11. Iwasaki A, Grubaugh ND. Why does Japan have so few cases of covid-19? EMBO Mol Med. 2020;12:e12481. 
12. Mandell LA, Wunderink RG, Anzueto A, Bartlett JG, Campbell GD, Dean NC, Dowell SF, File TM Jr, Musher DM, Niederman MS, Torres A, Whitney CG, Infectious Diseases Society of America, American Thoracic Society. Infectious diseases society of America/American thoracic society consensus guidelines on the management of community-acquired pneumonia in adults. Clin Infect Dis. 2007;44(Suppl 2):S27-72.

13. Tan C, Huang Y, Shi F, Tan K, Ma Q, Chen Y, Jiang X, Li X. C-reactive protein correlates with computed tomographic findings and predicts severe covid-19 early. J Med Virol. 2020;92:856-62.

14. Poggiali E, Zaino D, Immovilli P, Rovero L, Losi G, Dacrema A, Nuccetelli M, Vadacca GB, Guidetti D, Vercelli A, Magnacavallo
A, Bernardini S, Terracciano C. Lactate dehydrogenase and C-reactive protein as predictors of respiratory failure in covid-19 patients. Clin Chim Acta. 2020;509:135-8.

15. Peduzzi P, Concato J, Kemper E, Holford TR, Feinstein AR. A simulation study of the number of events per variable in logistic regression analysis. J Clin Epidemiol. 1996;49:1373-9.

Publisher's Note Springer Nature remains neutral with regard to jurisdictional claims in published maps and institutional affiliations. 